\title{
SPRING MEETING GROWS
}

\author{
Eight Topical Symposia Are Slated For An Expanded \\ Second Annual Spring Meeting Of The MRS, Set For San Francisco
}

The Second Annual Spring Meeting of the Materials Research Society, to be held April 15-18 in San Francisco, will feature more than twice as many symposia as the inaugural meeting last spring in Albuquerque. This is a response to the remarkably enthusiastic reception accorded the first Spring Meeting, where attendance was nearly double the anticipated number of participants.

\section{Meeting Chairpersons}

Chairing the meeting are three outstanding materials scientists. They are A. Wayne Johnson, Sandia National Laboratories; Susan M. Kelso, Xerox Corporation, Palo Alto Research Center, and K.S. Sree-Harsha, San Jose State University. They report their program has been organized on the themes of the materials properties of thin films and on electronic materials. One, on mass memory technologies, grows out of the Albuquerque meeting. The others are new. The Society anticipates the blending of topics will inspire cross-symposia interest among participants while delving with the usual MRS depth into the nuts-andbolts of the individual subjects.

\section{Eight Symposia Slated}

Offered at San Francisco will be what promise to be eight outstanding symposia, each authoritatively organized. They are:

- "Ion Beam Processes in Advanced Electronic Materials and Device Technology," chaired by F.H. Eisen, Rockwell, B.R. Appleton, Oak Ridge, and T. Sigmon, Stanford.

- "Microscopic Identification of Electronic Defects in Semiconductors," chaired by N.M. Johnson, Xerox Palo Alto, Steve Bishop, NRL, and G. Watkins, Lehigh University.

- "Thin Films: The Relationship of Structures to Properties," chaired by K.S. Sree-Harsha, San Jose State, and C. Aita, University of Wisconsin/Milwaukee.

- "Mass Memory Technologies," chaired by M.A. Bosch, AT\&T Bell Laboratories.

- "Applied Materials Characterization," chaired by W. Katz, General Electric, and Peter Williams, Arizona State University.

- "Materials Issues in Applications of Amorphous Silicon Technology," chaired by A. Madan, SERI, M.J. Thompson, Xerox Palo Alto, and David Adler, MIT.

- "XUV and X-ray Optics for Synchrotron Radiation," chaired by P.A. Pianetta, SLAC-Stanford, and J. Golovchenko, AT\&T Bell Laboratories.

- "High-Power Dielectric Optical Mirrors," chaired by
K.C. Jungling, J.K. McIver, and J.R. McNeil, all of the University of New Mexico.

\section{Purpose of Spring Meetings}

The decision to sponsor two major international meetings annually was made by the Society for several reasons. The

\section{Two major conferences annually \\ Expand the available offerings while \\ Permitting greater convenience and flexibility}

phenomenal growth in attendance at the Annual Meeting, held in the fall, resulted in symposia so overcrowded that the talks couldn't be fully appreciated. That meeting's East Coast location, also, was inconvenient for many West Coast and Asian participants. Further, the opportunity to repeat symposia after 18 months, rather than 12 or 24 , made a Spring Meeting on the West Coast a valuable option for MRS members.

The happy result has been that 500 materials professionals-nearly a third the number who attended the most recent Annual Meeting-participated in the inaugural Spring Meeting, the slate of offerings at the second meeting has expanded two-fold, and the total number of substantial topical symposia available to MRS members has been dramatically expanded. Notes MRS President "Woody" White: "The move to two meetings was timely. The materials community has embraced this expansion, as evidenced by the overwhelming participation, and the Materials Research Society has developed sufficient size and scope to sustain this growth. We expect both yearly meetings will continue to keep pace with the exciting developments in the field of materials."

\section{For More Information}

The active participation of its members in its sponsored meetings is encouraged by the Society. MRS Executive Director John Ballance (412-367-3003) has current information on the San Francisco Meeting, as well as other MRS events. The Chairpersons also can be contacted directly, Wayne Johnson at 505-844-8782, Susan Kelso at 415-494-4170, and K.S. Sree-Harsha at 408-277-2446. As with all of the Society's programs, complete information will be provided automatically to all MRS members through publications. 